\title{
Knockdown of the prognostic cancer stem cell marker Musashi-1 decreases radio-resistance while enhancing apoptosis in hormone receptor-positive breast cancer cells via p21 WAF1/CIP1
}

\author{
Fabian M. Troschel ${ }^{1}$ (D) Heike Palenta ${ }^{2} \cdot$ Katrin Borrmann $^{1} \cdot$ Kristin Heshe $^{1} \cdot$ San Hue Hua ${ }^{3} \cdot$ George W. Yip $^{3}$ (1) . \\ Ludwig Kiesel $^{2} \cdot$ Hans Theodor Eich ${ }^{1} \cdot$ Martin Götte $^{2}$ (D) $\cdot$ Burkhard Greve $^{1}$ (i)
}

Received: 27 April 2021 / Accepted: 13 July 2021 / Published online: 22 July 2021

(c) The Author(s) 2021

\begin{abstract}
Purpose While the stem cell marker Musashi-1 (MSI-1) has been identified as a key player in a wide array of malignancies, few findings exist on its prognostic relevance and relevance for cancer cell death and therapy resistance in breast cancer.

Methods First, we determined prognostic relevance of MSI-1 in database analyses regarding multiple survival outcomes. To substantiate findings, MSI-1 was artificially downregulated in MCF-7 breast cancer cells and implications for cancer stem cell markers, cell apoptosis and apoptosis regulator p21, proliferation and radiation response were analyzed via flow cytometry and colony formation. Radiation-induced p21 expression changes were investigated using a dataset containing patient samples obtained before and after irradiation and own in vitro experiments.

Results MSI-1 is a negative prognostic marker for disease-free and distant metastasis-free survival in breast cancer and tends to negatively influence overall survival. MSI-1 knockdown downregulated stem cell gene expression and proliferation, but increased p21 levels and apoptosis. Similar to the MSI-1 knockdown effect, p21 expression was strongly increased after irradiation and was expressed at even higher levels in MSI-1 knockdown cells after irradiation. Finally, combined use of MSI-1 silencing and irradiation reduced cancer cell survival.

Conclusion MSI-1 is a prognostic marker in breast cancer. MSI-1 silencing downregulates proliferation while increasing apoptosis. The anti-proliferation mediator $\mathrm{p} 21$ was upregulated independently after both MSI-1 knockdown and irradiation and even more after both treatments combined, suggesting synergistic potential. Radio-sensitization effects after combining radiation and MSI-1 knockdown underline the potential of MSI-1 as a therapeutic target.
\end{abstract}

Keywords RNA-binding proteins $\cdot$ Musashi- 1 - Breast cancer $\cdot$ Radio-resistance $\cdot$ p21 $\cdot$ Apoptosis

\section{Introduction}

Breast cancer remains the most common malignancy in women worldwide, thus carrying a significant burden of morbidity and mortality (Bray et al. 2018). Individual prognosis is mainly determined by the tumor's metastatic ability and therapy resistance (Sledge et al. 2014). Breast cancer stem cells (BCSCs) have been identified as key drivers of both features (McDermott and Wicha 2010). BCSCs constitute a cancer cell subpopulation of highly tumorigenic, chemo- and radio-resistant cells. They are known to exhibit several markers, including CD133, CD44 and aldehyde dehydrogenase (ALDH) (McDermott and Wicha 2010). Multiple pathways have been identified that contribute to stem cell maintenance. Among these, the notch pathway (including the notch protein family) has been linked to 
recurrence and metastasis of cancer (Meisel et al. 2020). Given their outsized importance for tumor initiation and progression, targeting BCSCs remains a key priority (McDermott and Wicha 2010).

Musashi RNA-binding proteins are one of the major players in maintaining breast cancer stem cell properties and consist of two isoforms, both with similar mRNA binding properties (Okano et al. 2005). Musashi-1 (MSI-1) is a small intracellular protein acting as a post-transcriptional gene expression regulator (Fox et al. 2015). It has been identified as a cancer stem cell marker in a variety of cancers (Fox et al. 2015). In breast cancer, it is known to support tumor growth (Wang et al. 2010) as well as stem-like capacities (Lagadec et al. 2014), mainly by upregulating the notch pathway (Wang et al. 2010; Lagadec et al. 2014). It has also been linked to decreased levels of $\mathrm{p} 21^{\mathrm{WAF} 1 / \mathrm{CIP} 1}$ (Wang et al. 2010), a cyclin-dependent kinase inhibitor and, as such, a key versatile cell cycle protein that tends to inhibit breast cancer cell growth (Kreis et al. 2019). In a previous study limited to triple-negative breast cancer (TNBC), our group first linked MSI-1 to cell death mediation, key to therapeutic success in breast cancer (Troschel et al. 2020). In this study, we set out to understand the prognostic significance of MSI-1 expression in breast cancer and subsequently investigated ramifications of targeting MSI- 1 for apoptosis and therapy resistance in hormone receptor-positive breast cancer cells.

\section{Materials and methods}

\section{Cell culture \& siRNA transfection}

The hormone receptor-positive, luminal breast cancer cell line MCF-7 derived from a 69-year-old patient in 1970 (Soule et al. 1973) was acquired from American Type Culture Collection (ATCC)/LGC Standards (Wesel, Germany). Cell line authenticity was confirmed via short tandem repeat (STR) analysis. Cells were cultured as previously described (Troschel et al. 2018). Culture conditions were $37^{\circ} \mathrm{C}$ with $5 \% \mathrm{CO}_{2}$. Cells were cultured in RPMI 1640 medium (PAN Biotech, Aidenbach, Germany). 1\% penicillin/streptomycin and 10\% FCS (both Thermo Fisher Scientific, Waltham, MA, USA) were added.

For transient transfection, two MSI-1 siRNAs were used in equal concentrations (Applied Biosystems, Thermo Fisher Scientific, sequences in Supplementary Table S1). siRNAs were concentrated to $20 \mathrm{nM}$ combined. Then, $4 \mu \mathrm{l}$ siRNA, $4 \mu \mathrm{l}$ Dharmafect transfection medium (Dharmacon, Lafayett, CO, USA) and $152 \mu \mathrm{l}$ Opti-MEM (Gibco, Thermo Fisher Scientific) were added to each well in a 6-well plate. Cells were incubated for $24 \mathrm{~h}$. Then, medium was replaced, and cells were cultured for another $48 \mathrm{~h}$ before subsequent experiments were started.

\section{Quantitative polymerase chain reaction (qPCR)}

The RNeasy Mini Kit was used to isolate mRNA after transfection according to manufacturer's instructions. Reverse transcription was performed with the High-Capacity cDNA Reverse Transcription Kit (all Qiagen, Venlo, The Netherlands). Finally, a Rotor-Gene Q machine was used for the chain reaction. Taq Man probes (all Applied Biosystems, Foster City, CA, USA) normalizing to $18 \mathrm{~S}$ expression were used (Supplementary Table S2). RNA quality was determined via biophotometer (Eppendorf, Hamburg, Germany) with A260/280 rates between 1.8 and 2.0 considered appropriate, as before (Troschel et al. 2018). Data are expressed as fold changes using the $2^{-\Delta \Delta \mathrm{Ct}}$ method comparing MSI-1 knockdown cells to controls.

\section{Western Blot}

Western Blot experiments were performed as previously described (Troschel et al. 2020). About $10^{7}$ cells were trypsinized and lysed. Subsequently, $30 \mu \mathrm{g}$ of whole protein was electrophoresed and transferred to nitrocellulose and thus used for immuno-detection. Antibody binding was visualized using ECL peroxidase blotting substrate (Thermo Fisher Scientific). Then, quantification of luminescence was performed with a Fusion SL System (Peqlab, Erlangen, Germany). Primary and secondary antibody details are shown in Supplementary Table S3.

\section{Mammosphere formation}

Equal numbers of control and MSI-1 knockdown cells were seeded into coated six-well plates (Greiner, Kremsmünster, Austria) $24 \mathrm{~h}$ after siRNA transfection. To generate sphere formation, Spheromax CSC Medium (Promocell, Heidelberg, Germany) was added. After 7 days, sphere formation was assessed macroscopically. Additionally, sphere area in $\mu \mathrm{m}^{2}$ was quantified microscopically. Here, we photographically compared four microscopic fields for controls and knockdown cells. For area quantification, we used a previously published ImageJ Macro (Ivanov et al. 2014).

\section{Apoptosis measurements}

Subsequent to washing with phosphate-buffered serum (PBS), cells underwent the Annexin V/propidium iodide (PI) assay (Thermo Fisher Scientific), as detailed by the manufacturer and as previously described (Greve et al. 
2009). Measurement was performed on a flow cytometer (CyFlow space, Sysmex/Partec, Münster, Germany) using FloMax software (Quantum Analysis, Münster, Germany) to visualize and manage flow data. For interpretation, the fourth quartile in the measurement graph indicated apoptotic cells as cells were positive for Annexin V (binding to phosphatidylserine as cell membranes lose lipid asymmetry during apoptosis), but negative for propidium iodide, showing cells were apoptotic but cell membranes remained intact (Crowley et al. 2016).

\section{Colony formation and radio-resistance}

After transfection as described above, predefined equal numbers of cells were mixed with Matrigel (MethoCult Express, StemCell, Vancouver, Canada) and seeded in cell culture dishes (Nunc, Langenselbold, Germany). After 10 days of incubation, number of cell colonies was determined. Colonies were defined as contiguous cell groups (clones) of more than 50 cells. The number of colonies in MSI-1 knockdown cell dishes was calculated relative to the number of colonies in control cell dishes to understand changes in cell proliferation patterns.

Clonogenic assays were also used for determination of radio-resistance. Here, cells were treated with 6 Gy of radiation from a clinical TrueBeam linear accelerator (Varian, Palo Alto, CA, USA). The dose was chosen to mirror 5 Gy doses from the GSE59732 dataset. After 10 days, colonies were counted as described above. Plating efficacy (PEf) was calculated as $\mathrm{PEf}=$ number of colonies/number of seeded cells. Surviving fractions (SF) were then determined as $\mathrm{SF}=\mathrm{PEf}$ (irradiated)/PEf (control).

\section{MTT (3-(4,5-dimethyl-2-yl)-2,5-diphenyltetrazolium bromide) cell viability assay}

MTT assays were performed as previously described (ElNadi et al. 2020). Briefly, 4000 cells/well of MSI-1 knockdown and control cells were seeded in 96-well plates $48 \mathrm{~h}$ after transfection and cultured for an additional $24 \mathrm{~h}$. Then, chemotherapy was added: specifically, varying doses of cisplatin, and doxorubicin were used. MTT reagent was added $72 \mathrm{~h}$ later and measurements were performed after $24 \mathrm{~h}$ at $570 \mathrm{~nm}$.

\section{Database gene expression analyses}

For survival analyses, we used all DNA microarray data available in the bc-GenExMiner (Jézéquel et al. 2012). To avoid overfitting and false-positive results, we used default settings (median MSI-1 expression as cutoff, logrank analyses) for three outcomes of disease-free distant metastasis-free and overall survival. In a secondary analysis, we investigated ER-positive breast cancers only.

For gene expression correlation analyses, we used all DNA microarray breast cancer samples available (Jézéquel et al. 2013). Again, we used default settings to avoid false detection rates due to multiple testing. The correlation tool provides Pearson correlations, including Pearson's $r$ and the respective $p$ value. These are the results presented in Table 1 .

Finally, we correlated MSI-1 expression and the Nottingham Prognostic Index (NPI) using the same database. Again, all available breast cancer cases were included (the database does not allow sub-stratification, e.g., by estrogen receptor positivity). For expression comparison, the Dunnett-TukeyKramer test was performed by the tool.

\section{ROC plotter}

To better understand associations between MSI-1 and chemotherapy response, we used the ROC plotter (Fekete and Győrffy 2019). Here, we checked all included breast cancer patients receiving "any chemotherapy" as the primary analysis with a secondary analysis for estrogen receptor-positive patients only. All other settings were the pre-programmed default settings. As results, the website then reported expression levels of MSI-1 with differences assessed with the Mann-Whitney $U$ test. Similarly, an AUC analysis was performed for the strongest cutoff with $p$ value and AUC statistic presented.

\section{GSE59732 and GSE59733 GEO dataset analyses}

For pre- and post-irradiation comparisons, we utilized the connected GSE59732 and GSE59733 databases. Here, gene expression profiling in response to radiation treatment is presented in 9 paired breast cancer patient samples (database GSE59733) as well as in cell lines (database GSE59732). We used all paired primary patient samples and the MCF-7 cell line data. Data are presented as $\log 2$ RMA signal.

Table 1 Correlation of gene expression based on DNA microarray data from the bc-GenExMiner tool

\begin{tabular}{lcll}
\hline MSI1 correlations & Pearson's $r$ & $p$ value & Patient $n$ \\
\hline Notch-1 & 0.11 & $p<0.001$ & $n=9417$ \\
Notch-3 & 0.05 & $p<0.001$ & $n=9650$ \\
Nanog & 0.07 & $p<0.001$ & $n=8776$ \\
Tdgf1 & 0.06 & $p<0.001$ & $n=4733$ \\
Nestin & 0.11 & $p<0.001$ & $n=9095$ \\
P21 (CDKN1A) & -0.03 & $p=0.008$ & $n=9650$ \\
\hline
\end{tabular}

Pearson's correlations were used and Pearson's $r$, respective $p$ value and number of measurements used are given. For more details, please refer to "Methods" section 


\section{All patients}

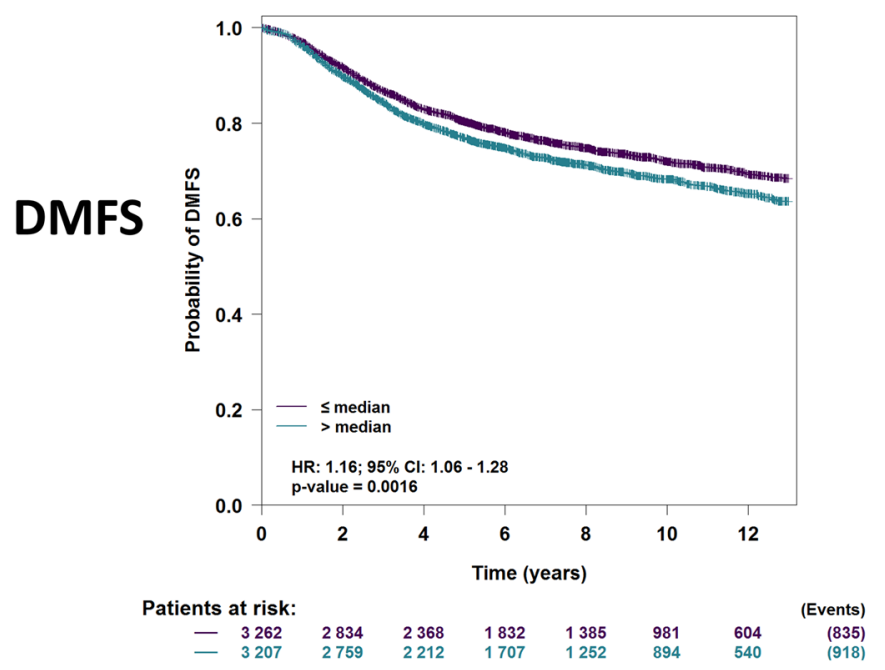

\section{ER-positive patients}

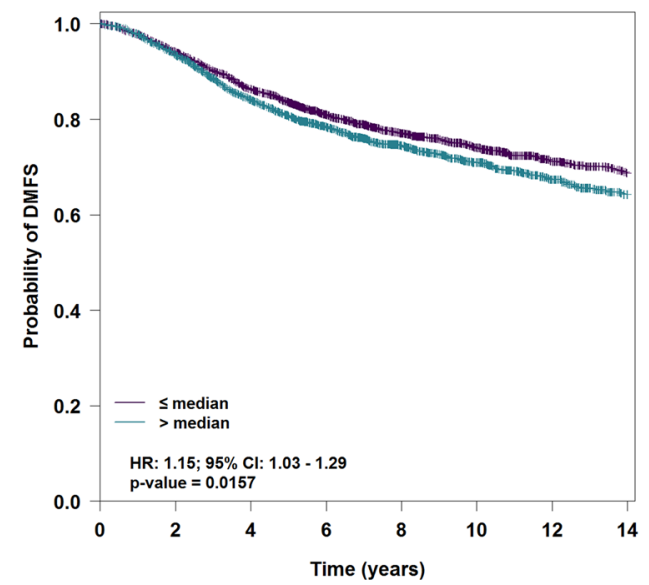

Patients at risk: (Events) $\begin{array}{rrrrrrrrr}-\quad 2367 & 2129 & 1824 & 1438 & 1091 & 765 & 479 & 332 & (570) \\ -\quad 2244 & 2019 & 1661 & 1298 & 959 & 681 & 416 & 257 & (592)\end{array}$

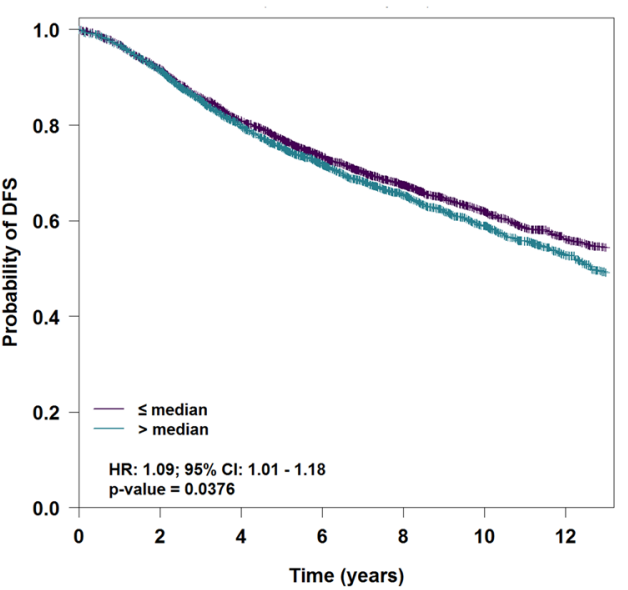

Patients at risk:

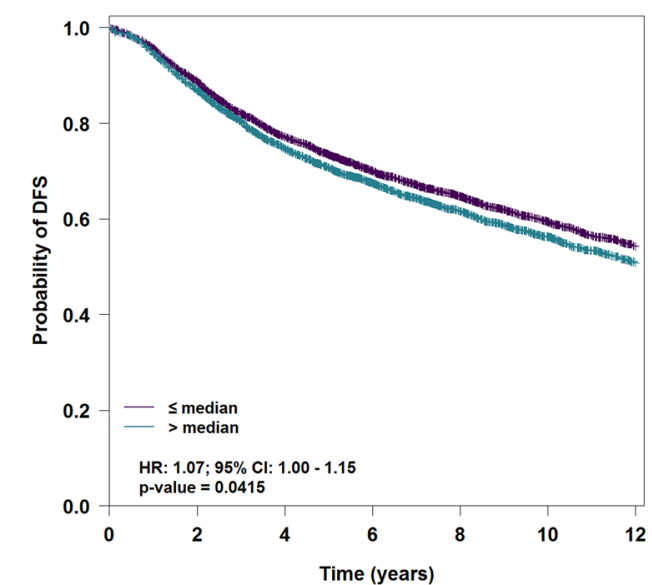

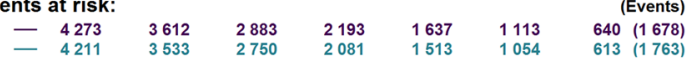

$\begin{array}{llll}\text { (Events) Patients at risk: } & & & \\ \text { (Events) }\end{array}$

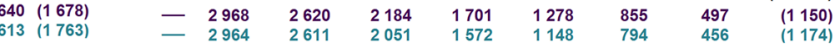

OS

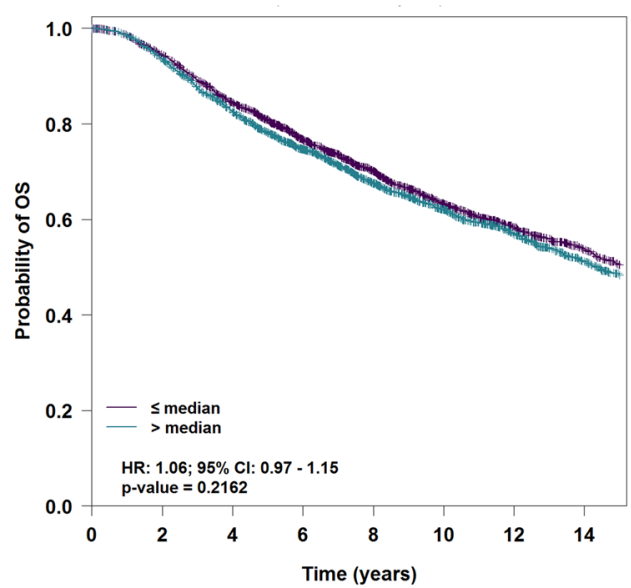

Patients at risk:

$\begin{array}{rlllllllr}-2404 & 2214 & 1911 & 1518 & 1182 & 849 & 587 & 398 & \text { (Events) } \\ -2400 & 2203 & 1875 & 1501 & 1159 & 858 & 600 & 388 & (1016)\end{array}$

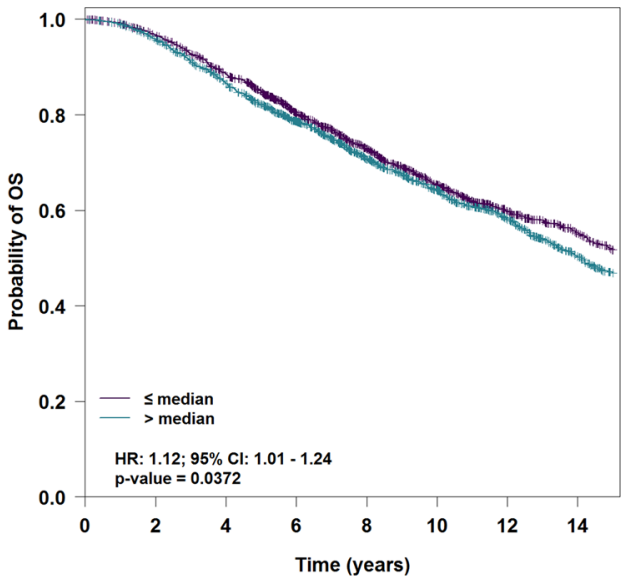

Patients at risk: $\begin{array}{lllllllllr}\text { 二 } & 1703 & 1605 & 1422 & 1141 & 902 & 646 & 452 & 324 & (685) \\ -\quad 1631 & 1534 & 1337 & 1094 & 857 & 642 & 445 & 282 & (703)\end{array}$ 
4Fig. 1 MSI-1 is associated with survival outcomes in breast cancer patients. Across all breast cancer patients (left column), higher than median MSI-1 expression results in decreased distant metastasisfree survival (DMFS, hazard ratio $[\mathrm{HR}]=1.16, p=0.0016$ ) and disease-free survival (DFS, HR $=1.07, p=0.042$ ) and tends to decrease overall survival (OS, HR $=1.06, p=0.22$ ). Similarly, in the estrogen receptor (ER)-positive group (right column), greater than median MSI-1 expression is associated with decreased DMFS $(\mathrm{HR}=1.15$, $p=0.016)$, DFS $(\mathrm{HR}=1.09, \quad p=0.038)$ and $\mathrm{OS} \quad(\mathrm{HR}=1.12$, $p=0.038$ ). Analyses (visualization and log-rank tests) were performed using the bc-GenExMiner tool (Jézéquel et al. 2012)

\section{Statistics}

All experiments were performed independently at least three times in duplicates. Student's $t$ test was used to assess differences. Level of significance was defined as $p<0.05$. Fold changes are visualized as mean \pm standard error of the mean (s.e.m.). For primary samples, paired $t$ test was used. Pearson correlation was used for expression correlation in the bc-GenExMiner database with $r$ and $p$ values given.

\section{Results}

\section{MSI-1 is a negative prognostic marker for multiple outcomes in breast cancer patients}

A previous study linked Musashi expression to overall survival (OS) in a small cohort of breast cancer patients (Wang et al. 2010). Here, we leveraged a large database of gene expression studies to characterize the association between MSI-1 and multiple outcomes including OS, disease-free survival (DFS), and distant metastasis-free survival (DMFS). We performed analyses both in all breast cancer samples and in hormone receptor-positive breast cancers only. Using the bc-GenExMiner tool (Jézéquel et al. 2012), we were able to identify MSI-1 as a negative prognostic marker for DFS and DMFS for all breast cancer patients and estrogen receptorpositive breast cancer patients only $(p<0.05$ in all cases, Fig. 1). Overall survival tended to be negatively associated with MSI-1 but was significantly associated with MSI-1 in estrogen receptor-positive patients only.

These findings informed our following studies to target MSI-1.

\section{MSI-1 knockdown results in downregulation of key stem cell markers, potentially rendering breast cancer cells vulnerable to anti-cancer signaling}

Similar to previous findings (Troschel et al. 2020), siRNAbased MSI-1 knockdown downregulated MSI-1 expression to a level of roughly $15 \%$ when compared to controls $(p<0.001)$. In western blot analyses, MSI-1 was downregulated as well, albeit less strongly ( $p<0.05$, Supplementary Figure S1).

We first reconfirmed that MSI-1 knockdown downregulated breast cancer stem cell characteristics: Mammosphere formation was significantly repressed following MSI-1 knockdown, both in number and in size, confirming previous findings (Supplementary Figure S2) (Wang et al. 2010). We then proceeded to investigate stem cell-related genes: given well-known associations with the notch pathway (Wang et al. 2010) we quantified notch-1 and notch-3, both of which were significantly downregulated by roughly $40 \%$ subsequent to MSI- 1 silencing ( $p<0.05$, Supplementary Figure S3). Expression of Tdgf1, a stem cell factor related to notch signaling sensitivity (Watanabe et al. 2009), but not previously reported as a MSI-1 regulatory target, was similarly decreased $(p<0.05)$.

Nanog, a transcription factor key to cellular reprogramming and a known breast cancer stem cell marker (Harati et al. 2019), was also expressed at lower levels ( $p<0.05)$.

Finally, Nestin, a stem cell intermediate filament (Asleh et al. 2018), was expressed less in MSI-1 knockdown cells, barely missing the level of significance $(p=0.052)$.

We then confirmed these correlations using the bc-GenExMiner tool (Table 1). In close to 10,000 breast cancer samples (using default settings to avoid multiple testing, thus including a heterogeneous cohort of all breast cancer patients available), notch-1 and notch-3 expression was positively associated with MSI-1. Similar trends were observed for Nanog and Tdgf1. In this analysis, Nestin was positively correlated with MSI1 expression, meeting the level of statistical significance. However, given the heterogeneity of the data (multiple datasets were pooled, different breast cancer types included and expression of the markers varied widely), Pearson's $r$ values were very low despite strong statistical significances.

These findings, including the identification of new additional stem cell markers attenuated after MSI-1 knockdown led us to hypothesize that breast cancer cells may be vulnerable to anti-proliferative and pro-apoptotic signaling.

\section{MSI-1 downregulation increases p21 expression in MCF-7 cells, resulting in increased apoptosis and decreased proliferation}

Besides notch pathway constituents and additional stem cell markers, the cell cycle protein p21 has been described as a regulatory target of MSI-1 (Battelli et al. 2006; Wang et al. 2010; Jadhav et al. 2016). Correlation analysis using the bc-GenExMiner database revealed a negative association between MSI-1 and p21 in breast cancer specimens (Table 1). For functional analyses, we next chose an MSI-1 siRNA knockdown approach in the ER-positive cell line MCF-7. In accordance with previous data (Wang et al. 


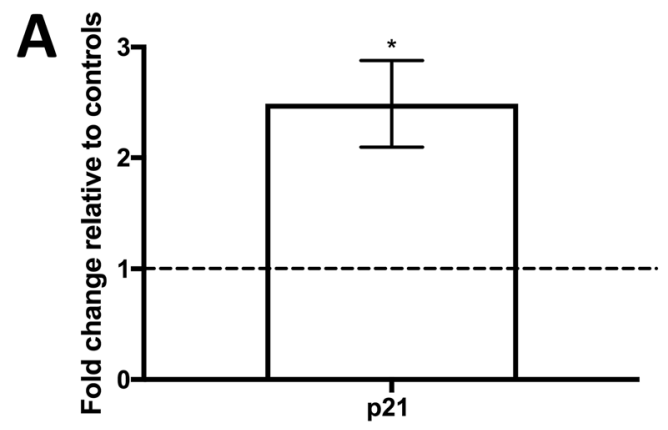

B

ctrl MSI-1-KD

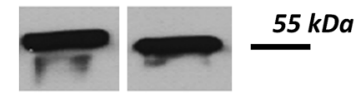

21

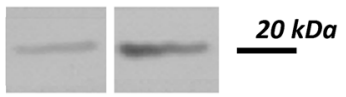

Fig. 2 Expression of p21 in MCF-7 cells after MSI-1 knockdown, compared to controls. Cells were transfected with a control siRNA and MSI-1 siRNA, respectively. Then, western blot measurements

2010), we observed a significantly stronger p21 expression in western blot investigations, more than doubling the control siRNA-transfected levels after MSI-1 knockdown in our experimental system (Fig. 2). and quantification were performed as detailed in the Methods section $(n=3, * p<0.05$, error bars indicate s.e.m.). Overall results are shown in panel $\mathbf{A}$; representative measurements are shown in panel $\mathbf{B}$

Given the decisive role of p21 in the regulation of breast cancer cell proliferation ( $\mathrm{Li}$ et al. 2020), we confirmed that colony formation was significantly downregulated after MSI-1 knockdown: clonogenic capacity was down by $25 \%$ (Fig. 3A).
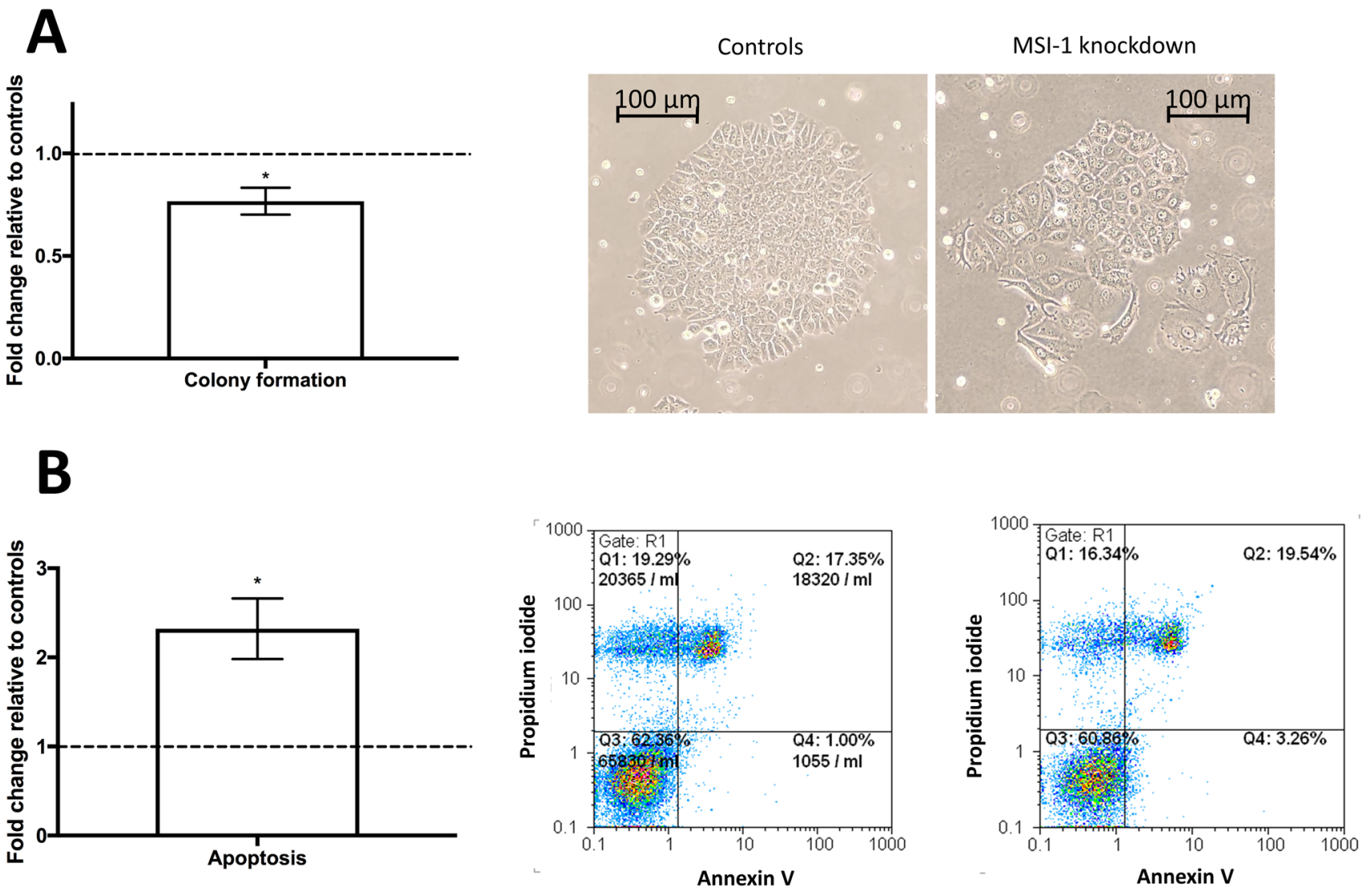

Fig. 3 Colony formation and apoptosis in MCF-7 cells after MSI-1 knockdown, compared to controls. Cells were transfected with a control siRNA and MSI-1 siRNA, respectively. A Colony formation is reduced after MSI-1 knockdown, a representative colony for control si-RNA transfected cells (middle) and MSI-1 knockdown cells (right) are also visualized. B Apoptosis is upregulated subsequent to MSI-1 silencing with representative images for controls (middle) and MSI-1 silenced cells (right). Apoptotic cells can be found in the fourth quartile (Q4, bottom right). Measurements were performed as detailed in the Methods section ( $n=3, * p<0.05$, error bars indicate s.e.m.) 
However, p21 has also been described to be a regulator of apoptosis and cell damage response (Weiss 2003). Thus, we also investigated apoptosis rates and found that MSI-1 downregulated cells were more than twice as likely to be apoptotic when compared with control siRNA-transfected cells (Fig. 3B).

\section{Irradiation increases p21 levels in MCF-7 and primary patient data}

After finding that MSI-1 knockdown increased p21 expression, we independently aimed to also understand irradiationinduced effects on $\mathrm{p} 21$. We thus compared expression of p21 after 5 Gy irradiation to cells with no irradiation in the MCF-7 cell line, utilizing the GSE59732 GEO database. P21 gene expression was significantly upregulated after irradiation (Fig. 4A). We were able to confirm the data using MCF-7 western blot experiments of our own, after a similar dose of 6 Gy (Fig. 4B).

We also utilized the connected GEO database GSE59733 of 9 patient breast cancer samples prior and subsequent to irradiation to compare p21 expression levels. There was a good correlation between pre- and post-radiation levels in the paired samples (Fig. 4C, Pearson's $r=0.55, p=0.11$ ), indicating that $\mathrm{p} 21$ levels reacted to irradiation consistently across all samples. In paired analyses, there was a strong $(p<0.001)$ increase in p21 levels after irradiation (Fig. 4D).

\section{MSI knockdown prior to irradiation leads to radiosensitization in MCF-7}

p21 has been described as a radio-sensitizer in breast cancer (Yang et al. 2012), as has notch pathway downregulation (Yahyanejad et al. 2016). Thus, we hypothesized that MSI-1 knockdown may increase radio-sensitization. First, we tested whether MSI-1 knockdown and irradiation had synergistic effects on $\mathrm{p} 21$ expression, as both treatments had similar effects on p21 levels independently from each other. After MSI-1 knockdown and 6 Gy of irradiation, p21 levels were expressed at higher levels when compared with control siRNA-transfected cells after 6 Gy irradiation (Fig. 5, representative blots in Supplementary Figure S4).

Subsequently, we showed that clonogenic ability is strongly reduced by about $50 \%$ in MSI-1-silenced cells compared to controls after irradiation (Fig. 5). This indicates an additional, irradiation-related effect added to the previously described anti-proliferative pro-apoptotic effect in non-irradiated cells, possibly via p21 overexpression.
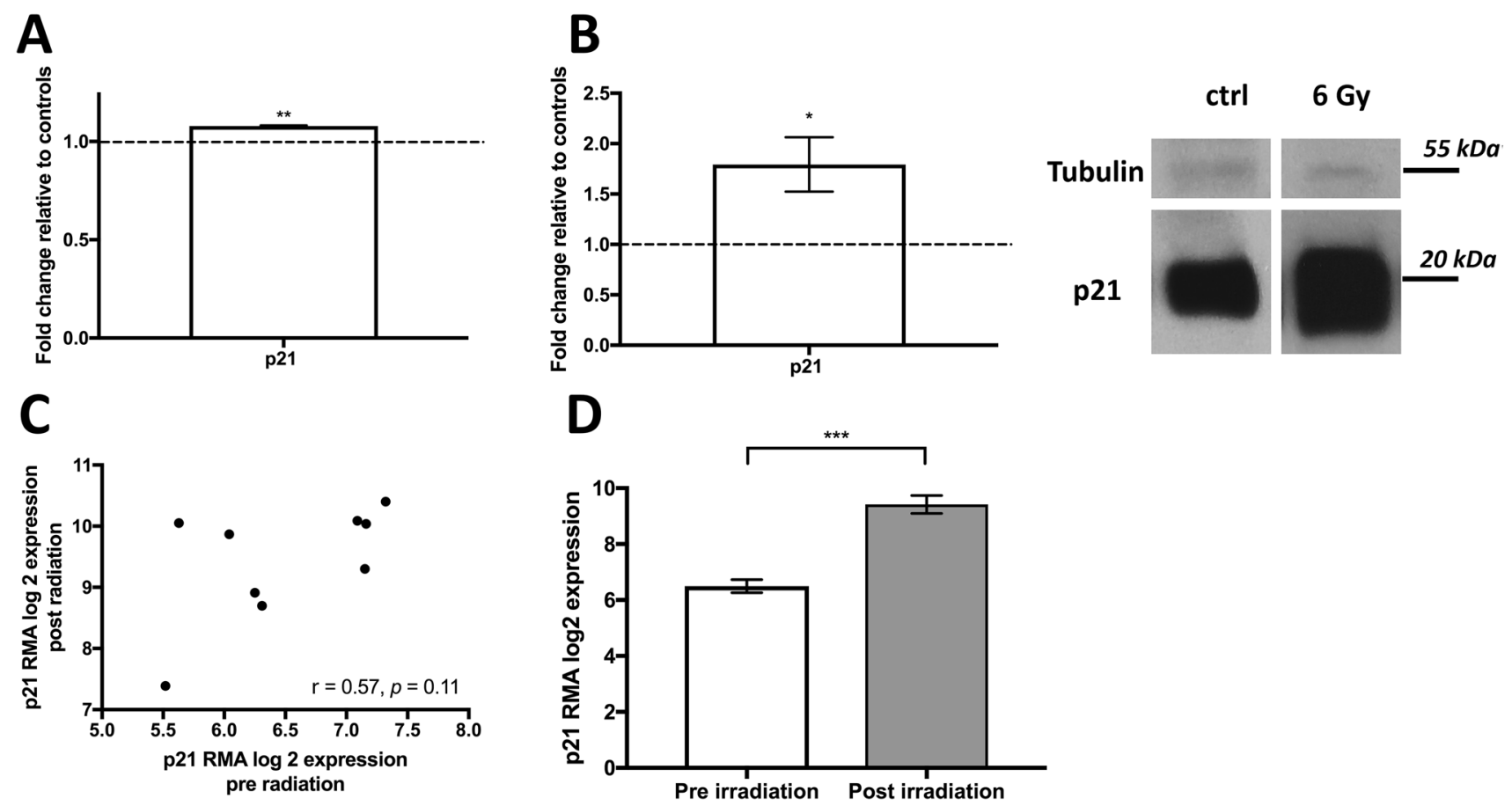

Fig. 4 Expression of p21 after irradiation. A p21 mRNA levels in MCF-7 cells after 5 Gy of irradiation as analyzed based on the GSE59732 dataset. B p21 protein levels in MCF-7 cells after 6 Gy vs. after no irradiation in our cell line experiment (left) with representative images (right) $(n=3, * p<0.05, * * p<0.01$, error bars indicate s.e.m.). Please note that tubulin and p21 were stained on the same gel simultaneously. As p21 was highly expressed gel exposure times were shortened, thus limiting tubulin staining. C Expression levels of p21 in 9 patient breast cancer samples pre- and post-irradiation as analyzed based on the GSE59733 dataset. Pearson's correlation analysis was performed. D Mean expression of p21 pre- and postirradiation. A paired $t$ test was performed $(* * * p<0.001$, error bars indicate s.e.m.). Data were normalized using Robust Multichip Average (RMA) 


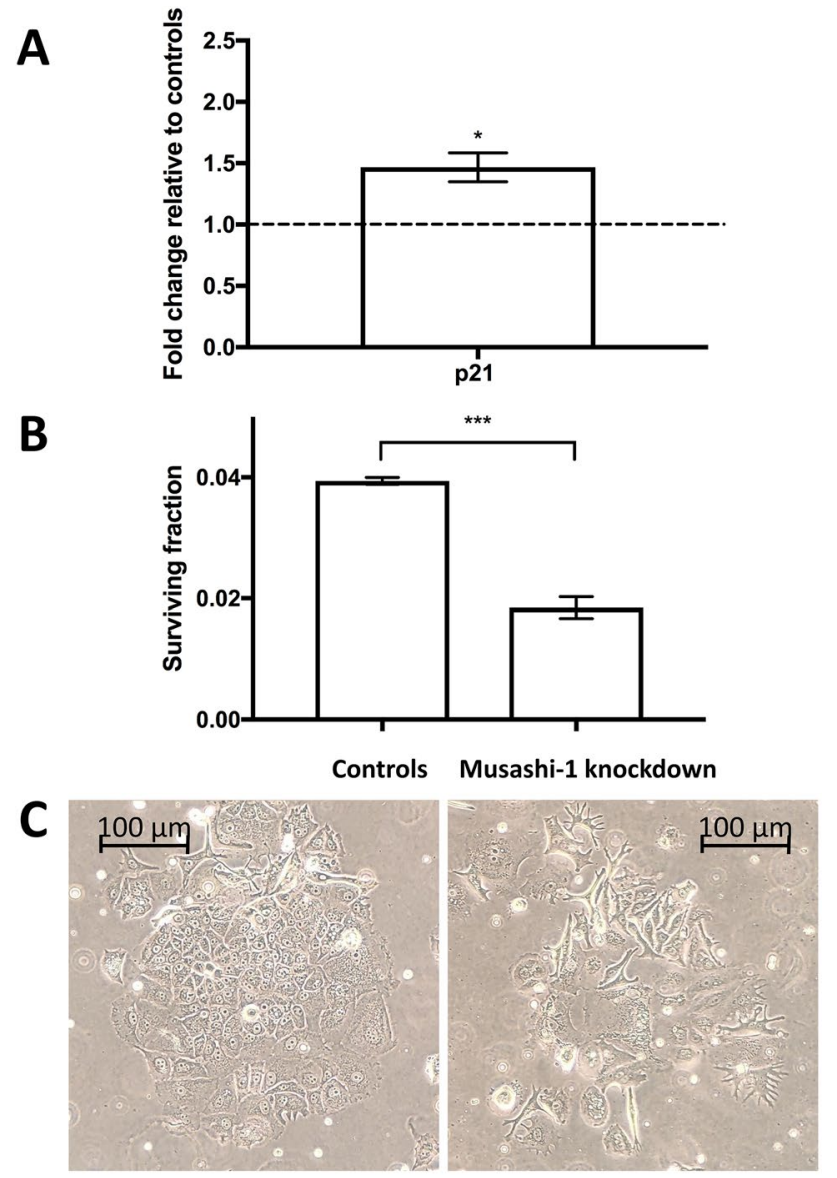

Fig. 5 Clonogenic survival after irradiation. A p21 is stronger expressed in MSI-1 knockdown cells after 6 Gy irradiation compared to control siRNA-transfected cells after 6 Gy. B Cells undergoing MSI-1-knockdown exhibited a strongly decreased clonogenic ability when compared to controls $(* p<0.05$, *** $p<0.001$, error bars indicate s.e.m.). C Representative images of a colony of control cells (left) and numerous, non-contiguous cells after MSI-1 transfection (right), both after a radiation dose of $6 \mathrm{~Gy}$

\section{Low MSI-1 expression is predictive of good chemotherapy response}

p21 has also been shown to be negatively correlated with chemoresistance (Hou et al. 2017; Mu et al. 2019). Thus, we hypothesized that MSI-1 knockdown may attenuate chemoresistance via p21 overexpression. Again using the bc-GenExMiner tool, we found MSI-1 to be associated with the Nottingham Prognostic Index (NPI) (Fig. 6A): here, MSI-1 expression is lowest in the least malignant NPI grade I and subsequently higher with highest expression in the most malignant NPI grade III $(p<0.05)$. The NPI is correlated with survival in breast cancer patients, underlining that MSI-1 has prognostic significance in breast cancer (Fong et al. 2015). However, the NPI is also known to be associated with chemoresistance, with NPI grade 3 associated with the highest chemoresistance (Tan et al. 2016), pointing to a relationship between MSI-1 expression and chemoresistance. Then, utilizing the ROC plotter data tool (Fekete and Győrffy 2019), we were able to directly connect MSI-1 expression and chemoresistance: using the "any chemotherapy" option (and default settings otherwise), patients with a complete response (CR) expressed significantly lower levels of MSI-1, both for all ( $p=0.016$, Fig. 6B) and for estrogen receptor-positive patients ( $p<0.001$, Fig. $6 \mathrm{C})$. Similarly, the receiver operating characteristic (ROC) analyses rendered significant results $(p<0.001$ for both groups). However, area under curve (AUC) values remained rather low ( 0.54 for all and 0.57 for ER-positive cases).

We subsequently followed these findings up with MTT tests in MCF-7 cells for cisplatin and doxorubicin. However, while a strong decline in viability was seen in MSI-1 knockdown cells before chemotherapy was added (Supplementary Figure S5A), no additional chemo-sensitizing effects became apparent (Supplementary figure S5B-D).

\section{Discussion}

In the present study, we investigated the significance of MSI-1 for survival outcomes in breast cancer as well as the molecular rationale for targeting MSI-1. We found that MSI-1 silencing resulted in reduced stem cell marker expression and cell proliferation while increasing apoptosis. When submitting MSI-1 downregulated cells to irradiation, a radio-sensitizing effect was seen.

\section{MSI-1 is a negative prognostic factor in breast cancer}

Leveraging the availability of large-scale data analysis tools, we provide an in-depth view of the negative prognostic role of MSI-1. While MSI-1 had previously been linked to overall survival in a small cohort of 140 patients (Wang et al. 2010), our findings from a large database provide a more nuanced perspective: while we were able to establish MSI-1 as a relevant factor for DFS and DMFS, we could only confirm an association with OS in hormone receptor-positive patients. In the entire cohort, there was a trend towards worse OS in MSI-1 high-expressing patients, but no significance was found $(p=0.2)$. Our findings regarding DMFS are supported by a previous study that reported that MSI-1 levels in nodal metastatic breast cancer were higher than in node-negative breast cancer (Wang et al. 2010). Besides breast cancer, MSI-1 is also prognostically relevant for other tumor entities, including colon cancer (Li et al. 2011) and glioblastoma (Vo et al. 2012).

Taken together, our analyses suggest a key role for MSI-1 for at least two of three main outcome parameters and a 
Fig. 6 MSI-1 expression is associated with chemoresistance. A MSI-1 expression is highest in Nottingham Prognostic Index (NPI) grade III breast cancer samples and consecutively lower across NPI II and NPI I. This figure was generated using the bc-GenEx-Miner tool (Jézéquel et al. 2013). B, C MSI-1 expression is lower in breast cancers with complete response to chemotherapy, both in all cancer tissues $(p=0.016$, B) and estrogen receptorpositive tumors only $(p<0.001$, C). This figure was generated using the ROC plotter data tool (Fekete and Győrffy 2019) and slightly amended to reflect statistical significances
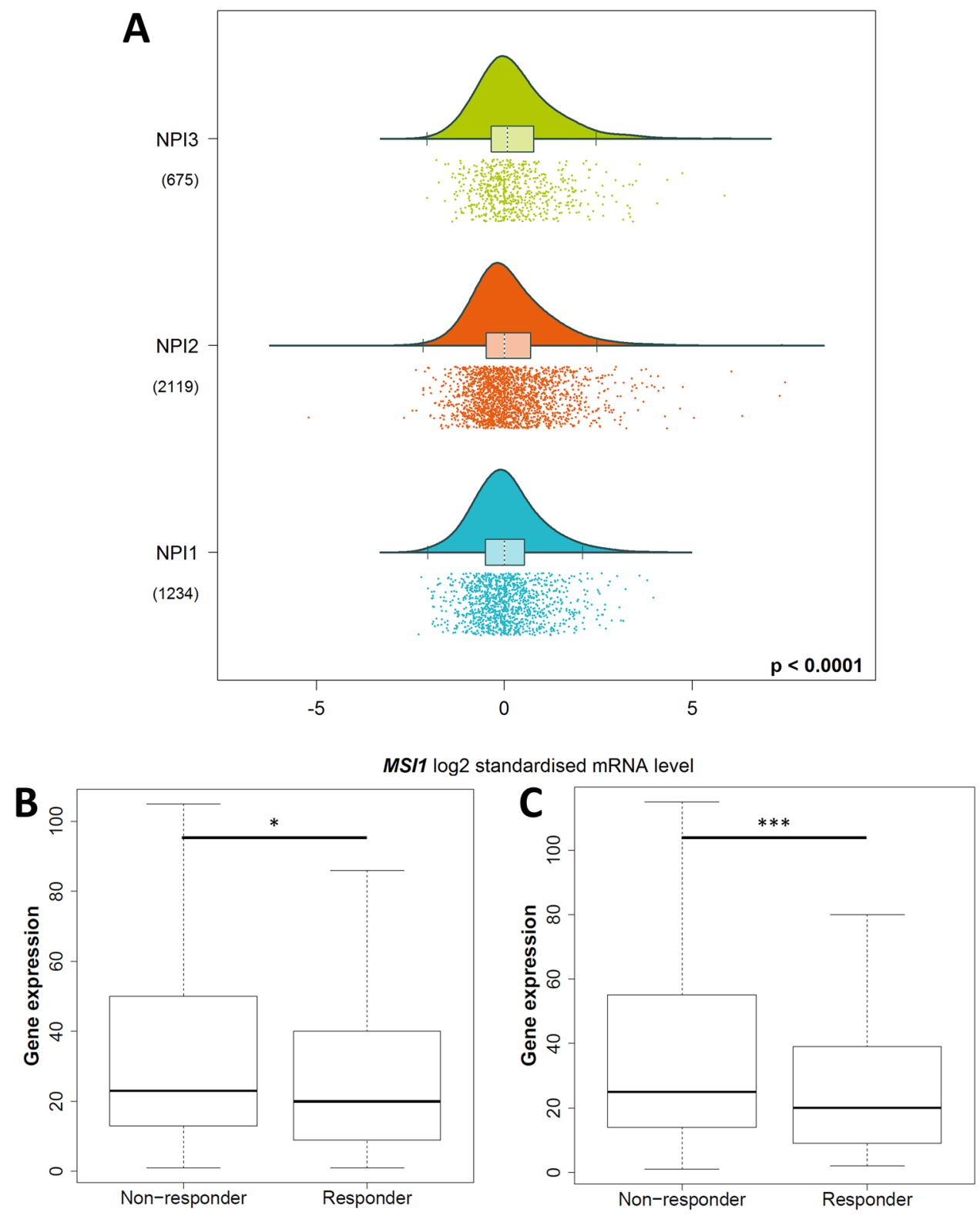

significant potential for MSI-1 targeting as a therapeutic approach.

\section{MSI-1 acts as a stem cell marker and modifier}

Previous studies indicate that MSI- 1 is a positive regulator of the notch pathway by directly targeting the notch repressor mnumb (Lagadec et al. 2014), thus supporting BCSC maintenance (Wang et al. 2010; Troschel et al. 2020). Our investigation reconfirms these findings as notch-1 and notch-3 were downregulated after MSI-1 silencing in MCF-7 cells. Subsequently, stem cell maintenance, as quantified by mammosphere formation (Cioce et al. 2010), was strongly repressed, similar to previous results (Wang et al. 2010). Mammosphere formation has also been correlated with tumorigenity in vivo, underlining the potential anti-tumorigenic effect subsequent to MSI-1 knockdown (Cariati et al. 2008). Additionally, Tdgf1, a factor not previously described as regulated by MSI-1 that sensitizes breast cancer cells to notch signaling (Watanabe et al. 2009), was also reduced. Notch-1, notch-3 and Tdgf1 were positively correlated with MSI-1 in the database analysis, underlining the evidence for MSI-1's role in maintaining notch stem cell signaling. Notch-1 is a poor prognostic factor in breast cancer (Zhong et al. 2016).

Nanog is another breast cancer stem cell marker (Jeter et al. 2016) that was negatively influenced by the MSI-1 knockdown. Our findings are thus in line with other breast cancer studies (Wang et al. 2010; Lagadec et al. 2014). Interestingly, Nanog is also known as a mediator of 
radio-resistance in breast cancer (Harati et al. 2019), offering further incentive to investigate radiation response. Besides, Nanog expression is also correlated with clinical stage (Saravi et al. 2019), well in line with MSI-1's prognostic relevance.

Nestin is a stem cell intermediate filament (Asleh et al. 2018). While there was only a positive trend between MSI-1 and Nestin expression in MCF-7 cells, the correlation met levels of significance in the dataset analysis. Nestin is an independent predictor of worse prognosis in breast cancer (Zhang et al. 2020).

Stem cell characteristics including notch pathway elements are associated with decreased apoptosis and increased proliferation (Suman et al. 2013). Thus, stem cell inactivation is a possible molecular mechanism behind increased apoptosis and reduced colony formation we observed after MSI-1 knockdown in this study.

\section{Role of p21 subsequent to MSI-1 knockdown for proliferation and apoptosis}

p21 is a well-known, yet controversial signaling molecule in breast cancer (Kreis et al. 2019). It is known to be a direct translational MSI-1 target (Battelli et al. 2006), including in breast cancer (Wang et al. 2010), thus explaining the upregulation seen after MSI-1 knockdown. P21 has been attributed several key characteristics.

In breast cancer, stem cell maintenance is known to be negatively regulated by p21 (Han et al. 2016). Conversely, stem cell maintenance is enhanced if p21 is downregulated (Jain et al. 2015). This is in line with our findings which demonstrate an increase of $\mathrm{p} 21$ and a decrease of stem cell characteristics subsequent to MSI-1 knockdown. It constitutes another mechanistic explanation for the loss of BCSC characteristics besides the MSI-1-mediated targeting of the notch repressor mnumb discussed above.

P21 has an anti-proliferative effect in breast cancer. When p21 is injected into a mouse model, breast cancer tumor growth is significantly repressed (Ibnat et al. 2019). Similarly, upregulation of p21 reduced (Wang et al. 2010) and downregulation promoted cell proliferation ( $\mathrm{Li}$ et al. 2020) in other studies. This is in line with our investigation which found proliferation to be strongly decreased after MSI silencing while $\mathrm{p} 21$ expression was increased.

While some investigations highlight an anti-apoptotic role for p21 (Fan et al. 2003), multiple studies have found that p21 has the potential to induce apoptosis if artificially upregulated (Jiang et al. 2014; Tor et al. 2015; Giordano et al. 2017). The specific role may hinge upon the cancer type or the exact intracellular localization of p21 with a nuclear localization linked to pro-apoptotic signaling (Crispi 2012; Shamloo and Usluer 2019). In this present case, p21 upregulation subsequent to MSI-1 downregulation had an anti-proliferative and pro-apoptotic effect.

Most studies have indicated that $\mathrm{p} 21$ is repressed in breast cancer cells compared to normal breast cells (Pellikainen et al. 2003). However, survival implications remain controversial (Zohny et al. 2019) and p21 has been described as both oncogenic and tumor-suppressive (Kreis et al. 2019). In this study, functional analyses indicate that MSI-1-dependent $\mathrm{p} 21$ upregulation is tumor-suppressive, similar to findings in endometrial carcinoma (Götte et al. 2011).

\section{MSI-1 downregulation radiosensitizes MCF-7 breast cancer cells and may lead to chemosensitization}

We found that MSI-1 downregulation results in a loss of clonogenic ability of MCF-7 cancer cells after irradiation. We irradiated cells with 6 Gy to reflect the 5 Gy radiation dose from the GSE59732 database we had previously used. The small discrepancy is due to technical reasons but is highly unlikely to have changed results in a significant way.

Presently, radiosensitization is an important aim for breast cancer research and therapy (Yahyanejad et al. 2016). This study suggests MSI-1 may be an interesting potential target to that end. Two possible explanations come to mind.

First, stem cells are known to be radio-resistant, specifically if notch and nanog signaling are high (Harati et al. 2019). The decrease in notch molecules and nanog expression seen after MSI-1 downregulation may thus explain the radio-sensitizing effect.

Second, the MSI-1-mediated p21 increase may also play a role. In our study, we show a similar effect of MSI-1 knockdown and irradiation on $\mathrm{p} 21$ expression: both independently increase p21 levels. Subsequently, we demonstrate that both treatments combined lead to higher levels of p21 than irradiation alone, suggesting synergistic potential. In turn, p21 overexpression may reduce proliferation while increasing apoptosis, resulting in a radiosensitizing effect with reduced clonogenic cell survival. In fact, previous investigations have linked p21 expression to radiosensitization in breast cancer (Yang et al. 2012; Kim et al. 2015; Xie et al. 2016).

MSI-1-mediated modulation of radiation resistance observed in the present study is in line with previous findings in glioblastoma (Lin et al. 2018), colon cancer (Sureban et al. 2008), and our previous findings in MDA-MB-231 TNBC cells (Troschel et al. 2020). They help expand the relevance of the radiosensitizing effect and establish MSI-1 as a potential target for improved radiotherapy-based cancer cell eradication.

Additionally, our database research demonstrates compelling evidence that MSI-1 knockdown may be associated with chemosensitization as low MSI-1-expressing tumors were more likely to have a less malignant NPI grade and to show a complete response after chemotherapy. However, 
AUC statistics indicated prognostic value was somewhat limited. We hypothesize that this may be due to breast cancer heterogeneity and the lack of granularity in the outcome variable (differentiating complete response vs. no complete response only). Additionally, previously published links between $\mathrm{p} 21$ and chemoresistance showing inverse correlations demonstrate a plausible mechanistic explanation for the effects (Hou et al. 2017; Mu et al. 2019). Unfortunately, our MCF-7 cell line data did not support the findings above, so the picture is not entirely clear here. We believe that the primary patient data offer arguably more compelling evidence. In vitro, the absence of the tumor microenvironment in our MCF-7 cell culture may have acted as a confounder (and even the MCF-7 data showed a strong decrease in cell viability through MSI-1 knockdown alone). Nonetheless, additional data are needed to substantiate MSI-1-based chemosensitization effects. In any case, MSI-1 knockdown demonstrated overwhelmingly favorable outcomes in the present research and continues to be an exciting scientific research opportunity.

Finally, it is worth discussing the effect of MSI-1 knockdown on cancer stem cells versus the general cancer cell population. As mentioned above, multiple studies, including the present work, suggest that MSI-1 may be a marker of cancer stem cells and/or linked to cancer stem cell maintenance. Limiting the effects mediated by MSI-1 to cancer stem cells only, however, would be insufficient to explain the findings of this study. While cancer stem cells undoubtedly play key roles in MCF-7, their percentage relative to the general population is very limited (Engelmann et al. 2008; Cioce et al. 2010; Li et al. 2017; Xu et al. 2018). As the changes in cell characteristics quantified in our experiments oftentimes reach significant strength, this points to changes in non-stem cells also. Our flow cytometric experiments further underline the effect on non-stem cells as cell histograms demonstrate uniform changes of the entire population towards a higher likelihood of apoptotic features. Importantly, effects do not seem to be limited to a subset of cells here. We thus assume that both cancer stem and normal cancer cells are changed by the MSI-1 knockdown.

However, normal cancer cells may not be directly affected by MSI- 1 loss, but rather indirectly by loss of cancer stem cells in the tumor environment. A cancer stem cell-rich microenvironment has been shown to substantially affect non-cancer stem cells (Bhat et al. 2019; López de Andrés et al. 2020). In any case, whether directly or indirectly, our findings support that MSI-1 loss affects a broad segment of cancer cells and is likely not limited to cancer stem cells.

There are several limitations to this study. First, while we rely on primary patient data for nearly all analyses, experimental proof-of-concept is performed in MCF-7 breast cancer cells only. Given the well-known heterogeneity of breast cancer, this limits applicability of the findings.
Second, the database gene expression correlations only demonstrate weak strength of associations. However, this is likely tumor heterogeneity in the database, as underlined by the fact that even neighboring notch- 1 and notch- 2 only demonstrate a Pearson's $r$ of 0.13 in the dataset. Thus, we hypothesize that low Pearson's $r$ values should not prematurely be discounted. Third, in western blot analyses, MSI-1 expression decrease after knockdown was less pronounced when compared to qPCR analyses. This is likely due to the binding of the other MSI protein family member, MSI-2, that is nearly identical with MSI-1 (Sakakibara et al. 2001), but was not targeted for knockdown. Finally, in accordance with this study's aim, not all associations seen via qPCR were confirmed via Western Blot, especially when not relevant to the key findings.

\section{Conclusion}

In conclusion, MSI-1 is a prognostically relevant marker in breast cancer. Silencing MSI-1 results in downregulation of stem cell gene expression and upregulation of cell cycle and apoptosis regulator p21. Functionally, loss of MSI-1 expression leads to decreased proliferation and therapy resistance and increased apoptosis in MCF-7 cells. The present study underlines the potential of MSI- 1 as a therapeutic target in breast cancer.

Supplementary Information The online version contains supplementary material available at https://doi.org/10.1007/s00432-021-03743-y.

Acknowledgements We thank Annette van Dülmen and Birgit Pers for expert technical assistance. We also acknowledge the Medical Faculty of Münster University (Dekanat der Medizinischen Fakultät, Universität Münster) for their clinician scientist program supporting F.M.T.

Author contributions Conceptualization: FMT, MG and BG; methodology: MG and BG; software: FMT, HS, and GWY; formal analysis: FMT, HP, KB and KH; investigation: FMT, HP, KB, KH, HS, GWY, LK, HTE, MG, BG; data curation: HS and GWY; writing-original draft preparation: FMT; writing — review and editing: FMT, HP, KB, KH, HS, GWY, LK, HTE, MG, BG; visualization: FMT; supervision: GWY, LK, HTE, MG, BG All authors have read and agreed to the published version of the manuscript.

Funding Open Access funding enabled and organized by Projekt DEAL. No funding was acquired for this study. Open access publication is supported by Project DEAL.

Availability of data and material The authors confirm that the data supporting the findings of this study are available within the article and its supplementary materials.

Code availability Not applicable. 


\section{Declarations}

Conflict of interest None of the authors report a conflict of interest regarding the study.

Ethics approval This is a database and in vitro study. No ethics approval was required.

Open Access This article is licensed under a Creative Commons Attribution 4.0 International License, which permits use, sharing, adaptation, distribution and reproduction in any medium or format, as long as you give appropriate credit to the original author(s) and the source, provide a link to the Creative Commons licence, and indicate if changes were made. The images or other third party material in this article are included in the article's Creative Commons licence, unless indicated otherwise in a credit line to the material. If material is not included in the article's Creative Commons licence and your intended use is not permitted by statutory regulation or exceeds the permitted use, you will need to obtain permission directly from the copyright holder. To view a copy of this licence, visit http://creativecommons.org/licenses/by/4.0/.

\section{References}

Asleh K, Won JR, Gao D et al (2018) Nestin expression in breast cancer: association with prognosis and subtype on 3641 cases with long-term follow-up. Breast Cancer Res Treat 168:107-115. https://doi.org/10.1007/s10549-017-4583-z

Battelli C, Nikopoulos GN, Mitchell JG, Verdi JM (2006) The RNAbinding protein Musashi-1 regulates neural development through the translational repression of p21WAF-1. Mol Cell Neurosci 31:85-96. https://doi.org/10.1016/j.mcn.2005.09.003

Bhat V, Allan AL, Raouf A (2019) Role of the microenvironment in regulating normal and cancer stem cell activity: implications for breast cancer progression and therapy response. Cancers 11:1-22. https://doi.org/10.3390/cancers 11091240

Bray F, Ferlay J, Soerjomataram I et al (2018) Global cancer statistics 2018: GLOBOCAN estimates of incidence and mortality worldwide for 36 cancers in 185 countries. CA Cancer J Clin 68:394-424. https://doi.org/10.3322/caac.21492

Cariati M, Naderi A, Brown JP et al (2008) Alpha-6 integrin is necessary for the tumourigenicity of a stem cell-like subpopulation within the MCF7 breast cancer cell line. Int J Cancer 122:298304. https://doi.org/10.1002/ijc.23103

Cioce M, Gherardi S, Viglietto G et al (2010) Mammosphere-forming cells from breast cancer cell lines as a tool for the identification of CSC-like- and early progenitor-targeting drugs. Cell Cycle 9:2878-2887. https://doi.org/10.4161/cc.9.14.12371

Crispi S (2012) The dual role played by p21 may influence the apoptotic or anti-apoptotic fate in cancer. J Can Res Updates. https:// doi.org/10.6000/1929-2279.2012.01.02.5

Crowley LC, Marfell BJ, Scott AP, Waterhouse NJ (2016) Quantitation of apoptosis and necrosis by annexin $\mathrm{V}$ binding, propidium iodide uptake, and flow cytometry. Cold Spring Harb Protoc 2016:953957. https://doi.org/10.1101/pdb.prot087288

El-Nadi M, Hassan H, Saleh ME et al (2020) Induction of heparanase via IL-10 correlates with a high infiltration of CD163+ M2-type tumor-associated macrophages in inflammatory breast carcinomas. Matrix Biol Plus 6-7:6-7. https://doi.org/10.1016/j.mbplus. 2020.100030

Engelmann K, Shen H, Finn OJ (2008) MCF7 side population cells with characteristics of cancer stem/progenitor cells express the tumor antigen MUC1. Cancer Res 68:2419-2426. https://doi.org/ 10.1158/0008-5472.CAN-07-2249

Fan Y, Borowsky AD, Weiss RH (2003) An antisense oligodeoxynucleotide to $\mathrm{p} 21 \mathrm{Waf} 1 / \mathrm{Cip} 1$ causes apoptosis in human breast cancer cells. Mol Cancer Ther 2:773-782

Fekete JT, Győrffy B (2019) ROCplot.org: validating predictive biomarkers of chemotherapy/hormonal therapy/anti-HER2 therapy using transcriptomic data of 3,104 breast cancer patients. Int J Cancer 145:3140-3151. https://doi.org/10.1002/ijc.32369

Fong Y, Evans J, Brook D et al (2015) The Nottingham Prognostic Index: five- and ten-year data for all-cause survival within a screened population. Ann R Coll Surg Engl 97:137-139. https:// doi.org/10.1308/003588414X14055925060514

Fox RG, Park FD, Koechlein CS et al (2015) Musashi signaling in stem cells and cancer. Annu Rev Cell Dev Biol 31:249-267. https://doi. org/10.1146/annurev-cellbio-100814-125446

Giordano C, Rovito D, Barone I et al (2017) Benzofuran-2-acetic ester derivatives induce apoptosis in breast cancer cells by upregulating p21 Cip/WAF1 gene expression in p53-independent manner. DNA Repair 51:20-30. https://doi.org/10.1016/j.dnarep.2017.01.006

Götte M, Greve B, Kelsch R et al (2011) The adult stem cell marker Musashi-1 modulates endometrial carcinoma cell cycle progression and apoptosis via Notch-1 and p21WAF1/CIP1. Int J Cancer 129:2042-2049. https://doi.org/10.1002/ijc.25856

Greve B, Dreffke K, Rickinger A et al (2009) Multicentric investigation of ionising radiation-induced cell death as a predictive parameter of individual radiosensitivity. Apoptosis 14:226-235. https://doi. org/10.1007/s10495-008-0294-6

Han S, Woo JK, Jung Y et al (2016) Evodiamine selectively targets cancer stem-like cells through the p53-p21-Rb pathway. Biochem Biophys Res Commun 469:1153-1158. https://doi.org/10.1016/j. bbrc.2015.12.066

Harati MD, Rodemann HP, Toulany M (2019) Nanog signaling mediates radioresistance in ALDH-positive breast cancer cells. Int $\mathrm{J}$ Mol Sci. https://doi.org/10.3390/ijms20051151

Hou M-F, Luo C-W, Chang T-M et al (2017) The NuRD complexmediated p21 suppression facilitates chemoresistance in BRCAproficient breast cancer. Exp Cell Res 359:458-465. https://doi. org/10.1016/j.yexcr.2017.08.029

Ibnat N, Kamaruzman NI, Ashaie M, Chowdhury EH (2019) Transfection with p21 and p53 tumor suppressor plasmids suppressed breast tumor growth in syngeneic mouse model. Gene 701:32-40. https://doi.org/10.1016/j.gene.2019.02.082

Ivanov DP, Parker TL, Walker DA et al (2014) Multiplexing spheroid volume, resazurin and acid phosphatase viability assays for highthroughput screening of tumour spheroids and stem cell neurospheres. PLoS ONE 9:1-14. https://doi.org/10.1371/journal.pone. 0103817

Jadhav S, Ajay AK, Trivedi P et al (2016) RNA-binding protein Musashi homologue 1 regulates kidney fibrosis by translational inhibition of p21 and numb mRNA. J Biol Chem 291:1408514094. https://doi.org/10.1074/jbc.M115.713289

Jain MV, Jangamreddy JR, Grabarek J et al (2015) Nuclear localized Akt enhances breast cancer stem-like cells through counter-regulation of p21Waf1/Cip1 and p27kip1. Cell Cycle 14:2109-2120. https://doi.org/10.1080/15384101.2015.1041692

Jeter CR, Yang T, Wang J et al (2016) Concise review: NANOG in cancer stem cells and tumor development: an update and outstanding questions. Stem Cells 33:2381-2390. https://doi.org/10.1002/ stem.2007.NANOG

Jézéquel P, Campone M, Gouraud W et al (2012) Bc-GenExMiner: an easy-to-use online platform for gene prognostic analyses in breast cancer. Breast Cancer Res Treat 131:765-775. https://doi.org/10. 1007/s10549-011-1457-7

Jézéquel P, Frénel JS, Campion L et al (2013) bc-GenExMiner 3.0: new mining module computes breast cancer gene expression 
correlation analyses. Database 2013:1-9. https://doi.org/10.1093/ database/bas060

Jiang D, Wang X, Liu X, Li F (2014) Gene delivery of cyclin-dependent kinase inhibitors p21 Waf1 and p27 Kip1 suppresses proliferation of MCF-7 breast cancer cells in vitro. Breast Cancer 21:614-623. https://doi.org/10.1007/s12282-012-0438-y

Kim MY, Park SJ, Shim JW et al (2015) Naphthazarin enhances ionizing radiation-induced cell cycle arrest and apoptosis in human breast cancer cells. Int J Oncol 46:1659-1666. https://doi.org/10. 3892/ijo.2015.2857

Kreis NN, Louwen F, Yuan J (2019) The multifaceted p21 (Cip1/Waf1/ CDKN1A) in cell differentiation, migration and cancer therapy. Cancers 11:1220. https://doi.org/10.3390/cancers11091220

Lagadec C, Vlashi E, Frohnen P et al (2014) The RNA-binding protein musashi-1 regulates proteasome subunit expression in breast cancerand glioma-initiating cells. Stem Cells 32:135-144. https:// doi.org/10.1002/stem. 1537

Li D, Peng X, Yan D et al (2011) Msi-1 is a predictor of survival and a novel therapeutic target in colon cancer. Ann Surg Oncol 18:2074-2083. https://doi.org/10.1245/s10434-011-1567-9

Li W, Ma H, Zhang J et al (2017) Unraveling the roles of CD44/ CD24 and ALDH1 as cancer stem cell markers in tumorigenesis and metastasis. Sci Rep 7:1-15. https://doi.org/10.1038/ s41598-017-14364-2

Li Y, Guo L, Ying S et al (2020) Transcriptional repression of $\mathrm{p} 21$ by EIF1AX promotes the proliferation of breast cancer cells. Cell Prolif. https://doi.org/10.1111/cpr.12903

Lin JC, Tsai JT, Chao TY et al (2018) MSI1 associates glioblastoma radioresistance via homologous recombination repair, tumor invasion and cancer stem-like cell properties. Radiother Oncol 129:352-363. https://doi.org/10.1016/j.radonc.2018.09.014

López de Andrés J, Griñán-Lisón C, Jiménez G, Marchal JA (2020) Cancer stem cell secretome in the tumor microenvironment: a key point for an effective personalized cancer treatment. J Hematol Oncol 13:1-22. https://doi.org/10.1186/s13045-020-00966-3

McDermott SP, Wicha MS (2010) Targeting breast cancer stem cells. Mol Oncol 4:404-419. https://doi.org/10.1016/j.molonc.2010.06. 005

Meisel CT, Porcheri C, Mitsiadis TA (2020) Cancer stem cells, quo vadis? The Notch signaling pathway in tumor initiation and progression. Cells. https://doi.org/10.3390/cells9081879

Mu X, Chen M, Xiao B et al (2019) EZH2 confers sensitivity of breast cancer cells to taxol by attenuating p21 expression epigenetically. DNA Cell Biol 38:651-659. https://doi.org/10.1089/dna. 2019.4699

Okano H, Kawahara H, Toriya M et al (2005) Function of RNA-binding protein Musashi-1 in stem cells. Exp Cell Res 306:349-356. https://doi.org/10.1016/j.yexcr.2005.02.021

Pellikainen MJ, Pekola TT, Ropponen KM et al (2003) p21WAF1 expression in invasive breast cancer and its association with p53, AP-2, cell proliferation, and prognosis. J Clin Pathol 56:214-220. https://doi.org/10.1136/jcp.56.3.214

Sakakibara SI, Nakamura Y, Satoh H, Okano H (2001) RNA-binding protein Musashi2: developmentally regulated expression in neural precursor cells and subpopulations of neurons in mammalian CNS. J Neurosci 21:8091-8107. https://doi.org/10.1523/jneurosci. 21-20-08091.2001

Saravi OE, Naghshvar F, Torabizadeh Z, Sheidaei S (2019) Immunohistochemical expression of nanog and its relation with clinicopathologic characteristics in breast ductal carcinoma. Iran Biomed J 23:184-189. https://doi.org/10.29252/.23.3.184

Shamloo B, Usluer S (2019) P21 in cancer research. Cancers 11:1-19. https://doi.org/10.3390/cancers 11081178

Sledge GW, Mamounas EP, Hortobagyi GN et al (2014) Past, present, and future challenges in breast cancer treatment. J Clin Oncol 32:1979-1986. https://doi.org/10.1200/JCO.2014.55.4139
Soule HD, Vazquez J, Long A et al (1973) A human cell line from a pleural effusion derived from a breast carcinoma. J Natl Cancer Inst 51:1409-1416. https://doi.org/10.1093/jnci/51.5.1409

Suman S, Das TP, Damodaran C (2013) Silencing NOTCH signaling causes growth arrest in both breast cancer stem cells and breast cancer cells. Br J Cancer 109:2587-2596. https://doi.org/10.1038/ bjc. 2013.642

Sureban SM, May R, George RJ et al (2008) Knockdown of RNA binding protein Musashi-1 leads to tumor regression in vivo. Gastroenterology 134:1448-1458. https://doi.org/10.1053/j.gastro.2008. 02.057

Tan W, Luo W, Jia W et al (2016) A combination of Nottingham prognostic index and IHC4 score predicts pathological complete response of neoadjuvant chemotherapy in estrogen receptor positive breast cancer. Oncotarget 7:87312-87322. https://doi.org/10. 18632/oncotarget.13549

Tor YS, Yazan LS, Foo JB et al (2015) Induction of apoptosis in MCF-7 cells via oxidative stress generation, mitochondria-dependent and caspase-independent pathway by ethyl acetate extract of Dillenia suffruticosa and its chemical profile. PLoS ONE 10:1-25. https:// doi.org/10.1371/journal.pone.0127441

Troschel FM, Böhly N, Borrmann K et al (2018) miR-142-3p attenuates breast cancer stem cell characteristics and decreases radioresistance in vitro. Tumor Biol 40:1-10. https://doi.org/10.1177/ 1010428318791887

Troschel FM, Minte A, Ismail YM et al (2020) Knockdown of Musashi RNA binding proteins decreases radioresistance but enhances cell motility and invasion in triple-negative breast cancer. Int J Mol Sci 21:2169. https://doi.org/10.3390/ijms21062169

Vo DT, Subramaniam D, Remke M et al (2012) The RNA-binding protein musashi1 affects medulloblastoma growth via a network of cancer-related genes and is an indicator of poor prognosis. Am J Pathol 181:1762-1772. https://doi.org/10.1016/j.ajpath.2012. 07.031

Wang X, Penalva LO, Yuan H et al (2010) Musashi1 regulates breast tumor cell proliferation and is a prognostic indicator of poor survival. Mol Cancer 9:221. https://doi.org/10.1186/ 1476-4598-9-221

Watanabe K, Nagaoka T, Lee JM et al (2009) Enhancement of Notch receptor maturation and signaling sensitivity by Cripto-1. J Cell Biol 187:343-353. https://doi.org/10.1083/jcb.200905105

Weiss RH (2003) p21Waf1/Cip1 as a therapeutic target in breast and other cancers. Cancer Cell 4:425-429. https://doi.org/10.1016/ S1535-6108(03)00308-8

Xie Y, Wang B, Tanaka K et al (2016) Enhancement of radiosensitivity of MCF-7 breast cancer cells subjected to X-ray or carbonion irradiations. Nucl Sci Tech 27:1-7. https://doi.org/10.1007/ s41365-016-0009-6

Xu Y, So C, Lam HM et al (2018) Apoptosis reversal promotes cancer stem cell-like cell formation. Neoplasia 20:295-303. https://doi. org/10.1016/j.neo.2018.01.005

Yahyanejad S, Theys J, Vooijs M (2016) Targeting Notch to overcome radiation resistance. Oncotarget 7:7610-7628. https://doi.org/10. 18632/oncotarget.6714

Yang D, Tan M, Wang G, Sun Y (2012) The p21-dependent radiosensitization of human breast cancer cells by MLN4924, an investigational inhibitor of NEDD8 activating enzyme. PLoS ONE. https:// doi.org/10.1371/journal.pone.0034079

Zhang X, Xing C, Guan W et al (2020) Clinicopathological and prognostic significance of nestin expression in patients with breast cancer: a systematic review and meta-analysis. Cancer Cell Int 20:1-17. https://doi.org/10.1186/s12935-020-01252-5

Zhong Y, Shen S, Zhou Y et al (2016) NOTCHI is a poor prognostic factor for breast cancer and is associated with breast cancer stem cells. Onco Targets Ther 9:6865-6871. https://doi.org/10.2147/ OTT.S109606 
Zohny SF, Al-Malki AL, Zamzami MA, Choudhry H (2019) p21 Waf1/Cip1: its paradoxical effect in the regulation of breast cancer. Breast Cancer 26:131-137. https://doi.org/10.1007/ s12282-018-0913-1
Publisher's Note Springer Nature remains neutral with regard to jurisdictional claims in published maps and institutional affiliations. 